\title{
THE ROLE OF ICT IN OPEN AND DISTANCE EDUCATION
}

\author{
Prof. Dr. Habibur RAHMAN \\ School of Social Sciences, Humanities and Languages \\ Bangladesh Open University, BANGLADESH
}

\begin{abstract}
Open and distance learning is getting more dependent on information and communication technology (ICT) and has been playing an important role in the delivery strategies of distance learning. With the advancement in technology in the field education has introduces variety of new techniques for educators and learners to enhance knowledge. Educational technologies (information and communication technology) are replacing direct teacher-student interaction. Anything that helps distance learners to communicate: learner with instructor, learner with learner and learner with the learning materials may be term as information technology. Technological advancements especially in the area of ICT allow teachers to employ various strategies that could actively engage student's interest. This paper focuses the role of information and communication technologies (ICT) in open and distance education. This study also explores technology-based media which is very important for distance learners.
\end{abstract}

Keyword: Open and distance education, technology, media and learning.

\section{INTRODUCTION}

Education is the basic need of every human being and today's technology has a big part in every sphere of life. In fact, Education is the most important investment by countries, societies, families and individuals for the future.

A communication network has become an essential tool in today's educational environment than ever before. Today's society is said to have entered into the age of a new social revolution, i.e. 'information revolution'. 21st century has witnessed the explosion of information technologies.

By digital revolution, technologies in computers, audio-visual devices, and communications are integrated into a powerful technology-information technology. The global era is characterized by rapid advances in technology and expansion of knowledge. Basically technology is nothing but a tool used in implementing our ideas and methodology in education. 
The application of new technologies in the distance education context provides an appropriate starting point for delineating the knowledge base required of expert teachers in today's global society. Teaching the distance learners requires different skills to prepare relevant learning materials to facilitate the construction of knowledge and learning.

The effective integration of ICT into the educational system is a complex, multifaceted process that involves not just technology- indeed given enough initial capital, getting the technology is the easiest part- but also curriculum and pedagogy, institutional readiness, teacher competencies and long term financing, among others.

Every country as they search for ways of using modern technology for educational purposes and development (Soh 2001). Open and distance education providers in both developed and developing countries, have been quick to realize the potential applications of the new information and communication technology.

It is well documented in the published literature and on Internet sites that on a worldwide basis the ICT an increasingly important role in education and training. Furthermore, it has been demonstrated that the use of ICT can improve the quality of the student learning experiences and make education and training opportunities available to a broader spectrum of the population in developing countries. At present educators are excited by the success of information technologies and want to implant them into instruction. They extol information technologies as the solution to break the barriers of time and space and fulfill the dream of life long education.

\section{METHODOLOGY}

The proposed paper mainly is descriptive-analytical in nature. Relevant books, articles and newspapers are used in this paper. Data and information are collected from the concern sources as per need to strengthen my research. Interpretative approach has been followed in this research.

\section{Distance Learning}

With the advancement in communication technology a variety of audio-visual mediaradio, television broadcast, video cassettes, video compact disc, video text, CD, computer and other innovative techniques are used for effective transmission of knowledge to the learners at a distance and open learning system. Open and distance learning is the second chance for those who are not able to continue their studies due to certain reason. Distance education on demand has been a way of reaching students who are unable to attend a traditional classroom base course. Due to increasing pressure in higher education, distance education is a reality in the present world. By definition, distance education denotes an educational experience where the teacher and the learner are not face- to- face during the teaching and learning process. The word "distance" in itself denotes separation of isolation and hence the criteria of being isolated are a "given" in distance education. 
"Distance education is planned learning that normally occurs in a different place from teaching necessitating special techniques of course design. Instruction, special method of communication by electronic and other media and special organization and administrative arrangements" (Moore and Kearsley).

Open and distance learning is defined by the Commonwealth of learning as "a way of providing learning opportunities that is characterized by the separation of teacher and learner in time, or place or both time and place; learning that is certified in some way by an institution or agency; the use of variety of media including print and electronic; two way communications that allow learners and tutors to interact; the possibility of occasional face to face meetings; and a specialized division of labor in the production and delivery of course (www.col.org) ".

Moore's(1989) definition of distance education as, " the separation between learner and teacher ,such that the communication between the two is necessary in the educational transition is transmitted through print, broadcasting, telecommunications media correspondence institution through the mail, audio and video recording, computers and various combinations and variations of these."

Distance education- the delivery of learning or training to those who are separated mostly by time and space from those who are teaching training. The teaching is done with a variety of "mediating process" used to transmit content, to provide tuition and to conduct assessment or measure outcomes (www.col.org).

Nipper (1989) was the first to suggest that distance learning was moving into its "third generation". Referring to correspondence education as the" first generation" model of distance learning and multimedia distance education as the "second generation" model. In these models little or no student-student and student-teacher interaction occurs.

Third generation of distance education, also known as interactive, multimedia distance education, places an emphasis on communication and learning as a social process typically through the addition of interactive media such as computer medicated communications, audio graphics or video conferencing. This third generation of distance education is based on the use of information technologies (Pelton, 1991, Taylor, 1992).

Taylor (1995) has further developed Nipper's ideas. With the combination of interactive multimedia (IMM) access to WWW resources, and asynchronous computer conferencing being designated as the "fourth generation" or "Flexible Learning "model.

The emerging fourth generation of distance education, the Flexible Learning Model, promises to combine the benefits of high quality interactive multimedia (IMM) with access to an increasingly extensive range of teaching- learning resources and enhanced interactivity through computer medicated communication(CMC) offered by connection to the Internet. 
One of the strengths of the Multi-media Model of distance education is that it has concentrated efforts on improving the quality of the student's individual interaction with learning materials. As Bates (1991) has highlighted that Social interaction between learners and teachers needs to be balanced with the individual student's interaction with teaching-learning resources including computer assisted learning program.

\section{USES OF ICT IN DISTANCE EDUCATION}

ICT are a potentially powerful tool for extending educational opportunities, formal and non- formal. ICTs also facilitate access to experts, resource persons, researcher, professionals, mentors, business leader, and peers- all over the world. For developing countries ICT have the potential for increasing access to and improving the relevance and quality of education. ICTs stand for information and communication technologies are defined, for the purpose of this primer, as a "diverse set of technological tools and resources used to communicate, and to create, disseminate, store and manage information." These technologies include computers, the internet, broadcasting technologies (radio, television) and telephony (Victoria, 2002). This may include all types of learning technologies such as print, audio, video and the computer. The use of computers in open and distance education has provided new pedagogical strategies in distance learning as well as giving more autonomy to the distance learners.

Technology has become a part of our life on campus, at home, and in the office. The modern technologies used in open and distance learning are telephone tutoring, teleconferencing, audio graphics, video conferencing, computer conferencing drill and practice, fiber optics, teletext, and videotext, multimedia and hypermedia CAI, e-books, the "Internet", the World Wide Web (WWW), or the "Information Super Highway" on-line database, on line discussion, call-in course- on demand, satellite, talk-back TV etc. All of these technologies should have a place in the knowledge base of expert teachers. A potentially useful framework for organizing such a knowledge base is provided by the emergence of different generations of distance education (Taylor, 1995)

In the concept of new technology, distance learning provides multimedia- based education content to the student utilizing standard data networking, protocols and infrastructure. The main advantages of using technologies in distance education are cost effectiveness, independence of time and place, quality of education access resulting from the mass production of course materials, teaching a lot of students simultaneously, and finding a lot of educational resources.

Haddad and Draxler (2002) identify at least five levels of technology use in education: presentation, demonstration, drill and practice, interaction, and collaboration. Each of the different ICTs-print, audio/video cassettes, radio and TV broadcasts, computers or the Internet-may be used for presentation and demonstration, the most basic of the five levels. Except for video technologies, drill and practice may likewise be performed using the whole range of technologies. 
On the other hand, networked computers and the Internet are the ICTs that enable interactive and collaborative learning best; their full potential as educational tools will remain unrealized if they are used merely for presentation or demonstration. The objectives of using technology must be very clear.

Technology is nothing but an enabling tool and it is the deconstruction of the course into its core experiences and its communication to the student regardless of its delivery mechanism that is crucial (Coble, 1996). The technology which can be integrated into the distance education system, based on our experiences, the following factors should be considered:

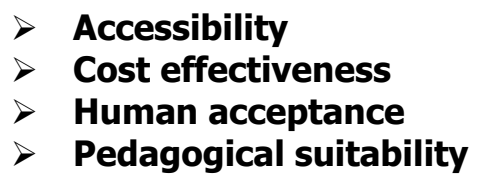

Emerging technologies have thus far afforded the development of a new generation of distance education using voice mail, e-mail, teleconferencing and computer- based integrated telecommunications and multimedia technology. It is hoped that these new educational technologies will enrich the distance interaction between teacher and student and the production of highly interactive self-paced learning packages used in the distance learning environment. This will be greatly beneficial to the distance learners who carry out their learning anytime and anywhere.

Importance of appropriate use of Technology-based Media

The information and communication technology-based media is very important for distance learners. In open and distance education different types of technologies and media are used to transfer education to the learners. Rumble $(1986,1994)$ said that four media namely print, audio, television computer are available for teaching purposes, in one technological form or another. A medium is a generic form of communication associated with particular ways of presenting knowledge. According to Prof. Bates (1993, 1995) there are five important media in education: direct human contract (face to face), text (including still graphics), audio, television and computing media (e. g. Internet, online technologies). The use of each media gives both variety and the chance of accommodating different learning styles. He goes on to argue that it is better to use a limited range of technologies in order to reduce redundancy and wasteful expenditure; provided all the main media are covered. One medium may serve a teaching function better than another in a particular area. The potential of each technology varies according to how it is used.

It is now -a -days more widely recognized that no single medium can be effective for all kinds of learning needs and that each technology has its own strength and weakness. For example, TV is very effective for teaching/learning, requiring pictorial or graphical illustrations, whereas print material is very effective and cost-efficient for the transmission of detailed information. 
Furthermore, the socio-economic, political cultural and geographical background of learners can influence their ability to learn using different forms of technology. A number of factors need to be taken into consideration when deciding upon the use of any one of the available technologies for course delivery and other purposes.

These include factors such as affordability, availability, access and the unique pedagogical characteristics of the particular technological application, instructional objectives financial resources available at the institution and student personal resources. The appropriate use of media and technology has provided information access to all students in remote, rural and urban areas as well as across nations.

There are a number of factors that need to be taken into consideration before deciding on the appropriate use of media and technology. Siddique (1987) stated that selection of appropriate media for a learning package is a complex decision influenced by a variety of considerations, such as the specific learning objectives of the unit, the nature of subject matter, learner's, background and experiences and the characteristics of the target group as well as practical constraints including availability of infrastructure and financial resources. However, managing technology is no simple task.

The emergence of new global economy has serious implications for the nature and purpose of educational institutions. Hence it is timely that academicians collaborate and cooperate at the national, regional and international level in the optimum utilization of technology to enhance the academic pursuit of knowledge while at the same time to achieving the noble mission of quality education for citizen of the universe. The teacher's guiding is the key factor in ensuring and enhancing the education quality in any education form.

\section{CONCLUDING REMARKS}

Education is the elementary right of human being for the development of a person both professionally and personally. With the emergence of technology especially in the field of open and distance education have open a new horizon for distance learners. Application of technology in education is not the ultimate goal; instead, we should use it to pursue quality. Information and communication technologies (ICT) are potentially powerful enabling tools for educational change and reform.

Rapid advances in information and communication technology pose new opportunities as well as challenges for every society. In the education sector, ICT has enormous potential to help countries address issues of access to learning, quality of the teaching-learning process and management of education systems. In order to ensure the quality of education, the distance education institutions must be careful about the use of proper technologies and media. We have to think the uses of media and technology in regard to appropriateness and acceptability in the society as well as on the ability of the institution offering the program. The socio-economic and cultural background of a person influences their ability to learn from different media technology. 
Effective combination of media and technology is necessary for assuring effectiveness of the open and distance learning system.

\section{BIODATA and CONTACT ADDRESSES of the AUTHOR}

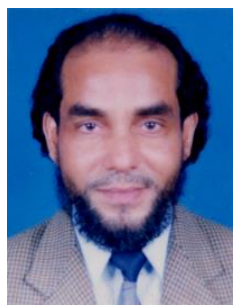

Dr. Mohammad Habibur RAHMAN is a Professor of Political Science at the School of Social Sciences, Humanities and Languages, Bangladesh Open University, Bangladesh. He was trained in the Fundamentals of design and writing of open and distance learning materials from the International Extension College (IEC), UK in 1998. He was a Visiting research scholar at the South Asia Institute, University of Heidelberg, Germany in 2001. He has published a several academic papers at the national and international level. Dr. Rahman is the author of Bangabandhu Sheikh Mujibur Rahman and Emergence of Bangladesh. He has a keen interest in open and distance education.

Prof. Dr. Habibur RAHMAN

School of Social Sciences, Humanities and Languages

Bangladesh Open University, BANGLADESH

Email: drhabib7@yahoo.com

\section{RFERENCES}

Bates, A. W. (1995). Technology, Open Learning and Distance Education, London: Routledge, 29-31

Bates, A. W. (1991). Interactivity as a criterion for media selection in distance education: Never Too far, 16: 5-9.

Barden, R. A. (1996). "The case for linear instructional design and development: A commentary on models, challenges and myths" Educational Technology, 2,5-23

Christina, S. (2001). The Use of Information technology for the management of Education in Singapore, Commonwealth Secretariat, London, United Kingdom.

Coble, W. (1996). Tele-learning: Deconstructing Courses. International Conference on Technology and Education, New Orleans, Louisiana, USA, March 17-20, pp. 416-18.

Haddad, W., \& Drexler, A. A. (2002). (eds) Technologies for Education: Potentials, Parameters, and Prospect, Washington D.C.: AED, Paris UNESCO

Moore, M. G., \& Kearsley, G. (1996). Distance Education: A systematic Approach, Belmont, CA, Wadsworth.

Moore, M. G. (1989). Distance Education: A learner's System, Lifelong Learning, Vol. 12, No.8 pp8-11. 
Moore, M. G. (1993). Theory and Practice in the use of technology in Keegan, D (ed).

Nipper, S. (1989). "Third generation distance learning and computer conferencing" in, Mason R. and Kaye A. (eds) Mindweave: communications, Computer, and distance Education, Pergamon Press Oxford, pp.63-73.

Pelton, J. N. (1991). "Technology and education: Friend or foe?" Research in Distance Education, 3, 2, 2-9.

Rumble, G. (1 995). Media use at Open University, The Guardian, (Dhaka, Bangladesh) Bangladesh Open University, November.

Rumble, G. (1986). Planning and Management of Distance Education, London: Groom Helm

Siddique, A. S. (1987). Role of Radio and TV in Distance Education System of Allama Iqbal Open University, Pakistan Journal of Distance Education. Vol. 5 No.2.

Taylor, J. C. (1995). Distance Education Technologies: The fourth generation, Australian Journal Educational technology, 11(2), 1-7

Taylor, J. C. (1992). Distance education and technology in Australia: A conceptual framework' International Council of Distance Education Bulletin, 28: 22-30

Victoria, L. Tino. (2002). ICT in Education, UNDP-ADIP, Kuala- Lumpur 